\title{
4
}

\section{Funerary speeches and marital investigations in highland Madagascar}

\author{
Denis Regnier
}

\section{Introduction}

The Betsileo are tireless walkers. In the countryside of the southern Malagasy highlands, walks are an essential part of daily activities. Men walk to the rice fields or to the forest, women walk to the garden or to the river and children walk to school or with the cattle they tend. And, of course, all of them walk to visit friends and relatives in other villages or to church, the grocery shop and the weekly market. The Betsileo countryside, as a result of myriad walks over generations, is crisscrossed with a striking network of laterite paths (Lalana) and narrow bridges across rivers.

The ubiquity of paths and the frequency of walks are crucial aspects of the Betsileo landscape, but they are equally crucial to their culture and social organisation. In this chapter, I focus on two specific kinds of 'walks' (fandehana-tongotra, from mandeha an-tongotra: 'to go by foot') or 'journeys' (dia) among the Betsileo: funerary speeches (tetiharana) and (pre)marital investigations (famotorana). Funerary speeches are walks only in a metaphorical sense, whereas marital investigations often require 'real' travelling on foot over long distances. Yet both cultural practices 
are conceptualised as journeys that have to be undertaken in particular situations. They are so closely connected they can be seen as the two faces of the same coin.

My starting point is research I first conducted for my $\mathrm{PhD}$ (Regnier 2012) and during several years of postdoctoral work (Regnier In press). It concerns the widespread discrimination against slave descendants among the southern Betsileo. A key aspect of the problem, as I have analysed it, is a strong pattern of marriage avoidance: Betsileo free descendants strictly refuse to marry slave descendants. I begin the chapter with background information on this avoidance of marriage with slave descendants among the southern Betsileo. I then explain what I mean by 'vigilance about origins', before describing funerary speeches as journeys in the context of Betsileo funerals and marital investigations as journeys in the context of customary marriage.

\section{Avoiding marriage with slave descendants}

Slave descendants in the southern highlands of Madagascar are viewed as inferior people and free descendants strictly refuse to marry them. Although other factors might also be important, the slave descendants' actual socioeconomic condition depends much on whether they own agricultural land (Regnier 2012, In press), work as sharecroppers for their former masters (Kottak 1980; Freeman 2013) or lead a semi-itinerant life (as described by Evers 2002), looking for karama (wage labour) in Betsileo country or beyond. In Beparasy, a region of the southern Betsileo highlands where I conducted fieldwork, the local slave descent group is rather fortunate: they own good rice lands and a significant number of zebus, and they also enjoy some prestige derived from the role of one of their ancestors in the settlement of the region (Regnier 2019).

The reasons for the discrimination against slave descendants among the southern Betsileo appear to be quite complex but, at the risk of oversimplifying, they can be summarised as follows. First, free descendants view slave descendants as irredeemably unclean (tsy madio) or dirty (maloto). They contend that marrying them will lead to mixing clean and unclean ancestries $(r a z a)$, so both their ancestors and the descendants of the 'mixed' couple will become unclean because of this. The children of a mixed couple will necessarily be unclean because the southern Betsileo 
apply a principle of hypodescent in the case of non-isogamous marriage. In consequence, if they bury unclean children in their tombs, free people will pollute these tombs and render the tombs' ancestors dirty.

The views I have just summarised constitute the most important emic reason for the marriage avoidance; this is how free descendants explained to me the problem they have with marrying slave descendants. But I have also sought to analyse the problem from an etic perspective and suggested that the discrimination and marriage avoidance can be further explained by a combination of historical and cognitive factors. I have argued that the colonial abolition of 1896 did not have the effects of a cleansing ritual, which was traditionally performed in the region when slaves were liberated (Regnier 2015). The Betsileo therefore continued to view the slaves liberated in 1896 as ritually unclean and, as a result, they avoided marrying them. I contend that, because of this early pattern of marriage avoidance in the aftermath of abolition, the free descendants have come to strongly essentialise-in the sense of psychological essentialism (Gelman 2003) —slave descendants, to the point that they now think that slave descendants cannot become clean persons again. Since cleansing unclean people was possible in the precolonial past and the condition of being unclean was thus considered transient, this would mean that a 'cognitive shift' occurred in the aftermath of the abolition (Regnier 2015). This is an etic standpoint insofar as the southern Betsileo do not see any shift in the way they view slave descendants; they seem to consider that they have 'simply' inherited views that existed in the precolonial past.

The essentialist construal of the categories of 'clean' and 'unclean' people, as well as the rule of hypodescent, is not easy to reconcile with the fluidity, performativity and optative nature of Malagasy kinship, identity and personhood as has been described during several decades by ethnographers such as Astuti (1995), Bloch (1993), Huntington (1988), Southall (1986), Wilson (1992) and others. The case of Betsileo slave descendants, whose social identity as 'unclean people' is ascribed at birth by free descendants, provides an alternative to this model. This competing model of social identity appeared in the southern highlands as a direct consequence of colonialism and colonial abolition.

In the southern Betsileo postcolonial context, it is therefore crucial for free descendants to check the ancestry (raza), origins (fiaviana) or roots (fototse) of their marriage partners. I called this culturally specific attitude a permanent 'vigilance about origins' because it pervades everyday 
encounters and forms of communication (Regnier 2019). I have already mentioned the two cultural practices that stand out as particularly effective ways of checking origins: funerary speeches and marital investigations.

\section{Funerary speeches}

Funerals are central events in the social life of the small rural community of Beparasy. The Betsileo had elaborate funerals in the past, especially for their 'nobles' (hova), whose bodies underwent ritual transformations, but the combined influences of colonisation and Christianisation have considerably altered these customs. Today's funerals are shorter than they were in the past - they usually last for only a few days - yet they remain socially important events and every Beparasy adult who is related to the deceased's family should pay a visit, participate in the several-day-long vigil in the village, attend the burial, eat a communal meal and listen to the funerary speeches.

In a nutshell, funerals in Beparasy can be described as follows: when a person dies, senior members of their family —ideally, on both parental sides-meet up to decide where (that is, in which village) the funeral will take place and where (that is, in which tomb) the deceased will be buried (Parker Pearson and Regnier 2018). The deceased is then brought to the village and the body is washed in a house by relatives, following specific rules and ancestral customs. The deceased is dressed up and placed in a room on the ground floor of a house, on a bed and inside a trano vorona - that is, a kind of 'house' placed over the bed and made of thin white cloth. This room is called the tranom-bavy (women's house) and that is where the family, mostly women, will keep a vigil over the dead person, praying and singing during several days and nights. When they arrive, visitors will go to the tranon-dahy (men's house)—usually a room upstairs in another house, very close to the house where the tranom-bavy is located. In this room, senior family members (mostly men) greet visitors, thank them for their arrival and explain the circumstances of the death. The visitors then announce the gifts they have brought to the bereaved family to participate in the funeral. Usually these gifts consist of rice, cloth (lamba), mats, cattle or a small amount of money. The gifts are recorded in notebooks so the family can reciprocate them in the future. If they have come from afar, the visitors are allocated a house in the village where they will be hosted and fed during the several days of the funeral. 
It is compulsory for the family organising the funeral to slaughter one or more cattle, since they have to feed their guests with rice and boiled meat. Cattle meat at funerals is called hena ratsy ('bad meat') and at the end of the event the remaining meat is distributed to the guests, who will take it home and consume it with their family.

Tetiharana are speeches that are pronounced on the kianja ratsy ('bad court' - that is, the open space or clearing close to the village that is used for funerals), where all the deceased's relatives and their guests gather after the burial, for what is called the fiefana ('completion'), which marks the end of the several-day-long funeral. During the fiefana, people sit on the ground and listen to the various speeches by family representatives, who recall the circumstances of the death and explain how the funeral was accomplished, stressing that everything was done according to traditional customs and, notably, that relatives and the 'government' (fanjakanathat is, the state) were informed of the death and the taxes for holding a funeral were paid. They also thank all the guests and families involved, citing the names of those who have brought substantial gifts to the organiser of the funeral. If the deceased was a Christian, religious songs are sung and a catechist may also read passages from the Bible. Then come the tetiharana speeches, which are often the most eagerly awaited moment of the concluding stage of a funeral.

During the days preceding the burial, tetiharana speakers will have memorised the accounts of family history that are written in the notebooks kept by the heads of the local descent groups. If the speakers found gaps in these accounts, they would have questioned their family elders. The tetiharana starts with a telling of how the first male ancestor of the deceased's patrilineal group is said to have arrived in Beparasy, after having alluded to previous ancestors and their regions of origin. The name of this first local ancestor is mentioned, and so is his descent group name. Then his wife is named, as well as her descent group and her village of origin. The name of the village they founded, or where they originally settled, is recalled, followed by the names of their children. The speech goes on with the offspring of the couple's children over generations, always providing the same information until it reaches the deceased. Once the tetihara of the patrilineal founding ancestor is over, another speaker, on the side of the deceased's mother, should follow. At least two tetihara speeches should be given (one on the paternal side and one on the maternal side) but sometimes other tetihara are added-for example, those of the deceased's FM's or MM's groups. The structure of the tetihara speech is of 
particular interest because its narrative recalls not only the names of the descendants of an ancestral couple, but also their geographical dispersion, mentioning migration and postmarital residence. Importantly, it also gives information about the marriages of the apical ancestor's descendants, since it names their spouses, their descent group and the villages from which they come. The tetiharana is therefore much more than a recounting of the members of a local descent group to which the dead belongs; it offers a mapping of the marital alliances that this local descent group has contracted with other groups in the past four or five generations. Narivelo Rajaonarimanana (1996: 38-39) translates tetiharana as parcours-derocher - that is, 'going through the rocks' or 'wandering through the rocks' (mitety: 'going through'; harana: 'rocky mountain')—and suggests that the word refers to the tombs that are often located in the mountains in southern Betsileo country. Giving a genealogical speech is like 'wandering through the rocks'; it is a metaphorical journey among the tombs and the ancestors. The tetiharana can thus be seen as both a genealogy and, borrowing from James Fox (2006), a 'topogeny'.

Since tetiharana speeches should be given by both parental sides of the deceased, when a marriage between free and slave descendants has taken place, it is deemed extremely shameful (hafa-baraka) to have the marriage spoken about in a tetiharana. In such cases, the families agree to skip the tetihara speeches, at the demand of the free descent side. This dissimulation, I was told, is not necessary when a 'mixed' marriage with a descendant of a noble has occurred in the family, since even though they are disapproved of for the reasons explained above, there is nothing intrinsically shameful in being allied with a family of noble descent and the tetiharana can be given.

The importance of tetiharana at funerals is crucial for southern Betsileo local descent groups since it is a way of demonstrating their 'clean' origins and the cleanliness of their marital alliances. In consequence, skipping tetiharana because of an inappropriate marriage in the family is not an easy decision; the guests may speculate that the family has something to hide. I was told, however, that it is sometimes better than taking the risk of being publicly seen to be allied with a family considered to be of slave descent, since the status of being unclean (tsy madio) could be ascribed to the whole family that has allowed one of its members to marry a slave descendant. Expressions such as 'lowering the ancestry' (manambany ny raza) are used to say that the person who marries a slave descendant will lower the status of the dead/ancestors but also that of the group as 
a whole and, consequently, the status of all its members. We have here an explanation of why the members of southern Betsileo descent groups are so adamant about not letting one of their own marry inappropriately. This is true for the senior members heading the group, but junior members, too, need to worry: if their family is suspected of being of slave descent or of marrying slave descendants, they will increasingly have difficulties finding a spouse with 'clean' origins for themselves or for their children.

The southern Betsileo feel they all know each other-in spite of their mobility, incessant migrations and population growth-because of the tetiharana speeches given at funerals. Through this means they keep alive the memories of origins, alliances and migrations-memories that are distributed across all people who live and regularly attend funerals in a particular region. I was often told that tetiharana speeches provide the best opportunities to learn about someone's slave descent or at least to become suspicious about the possible slave origins of some families. It is noteworthy that southern Betsileo's memories of alliances and ancestry are, like the tetiharana, essentially topogenic. The names of villages, particularly those of incoming spouses, are what may provoke suspicions that some of the descendants recounted in the tetiharana have slave origins.

\section{Customary marriage}

Vigilance about places of origins reaches its highest level among free descendants when parents are informed by their children that they are seeing someone and would like to perform the marriage customs. Since customary Betsileo marriage often consists of a long process involving exchanges of increasing formality and 'seriousness', free descendants have much time to check their potential marriage partner's origins (fiavina) and clean status. In what follows, I describe the process of customary marriage, to give a sense of the context in which the marital investigations take place.

The first steps in the process start as soon as teenagers become sexually active. Young men and women enjoy relative sexual freedom. When girls reach puberty, their parents often give them the option of moving to a separate room in the house, where they will sleep away from their brothers, because of the incest taboo, and where they will be able to host their lovers (sipa) for the night. Other sexually active female relatives, 
often sisters, can share the room. If the family house is two-storey, the room for the girls is always on the ground floor, whereas the parents occupy the first floor.

The room's location on the ground floor makes it easily accessible to lovers, who come after dusk and leave before dawn so that the girl's father, brothers or other male relatives do not see them. The furtive nature of these nocturnal visits does not mean that parents are unaware that their daughters see lovers at night. On the contrary, the girls are given the option of a separate room precisely to allow them to see their lovers without having to leave the house at night, which is considered a dangerous thing to do. It also prevents them from being forced to engage in more serious relationships, which would be the case if they were to introduce their lovers to their parents. For these affairs, it is always the boy who comes to the girl's place, and never the reverse. Yet sexual encounters are not limited to nocturnal visits or the confined space of the girl's room. They also happen during the day, often in the late afternoon, on a discreet riverbank or in some nearby undergrowth. Market days offer particularly good opportunities to meet up with lovers, as do all sorts of large gatherings or ceremonies, including funerals (Dubois 1938; Kottak 1980).

If a boy is accidentally seen by a male relative of the girl, or if he wants to be able to come to see his girlfriend without hiding himself, he has to give the 'closing of the eyes' (tapi-maso), which is the first formal relationship of exchange between a potential husband and his potential in-laws. The boy pays a small sum of money, which will be divided between the males of the girl's family, including her brothers. The boy, however, does not give the money directly to the father-which is taboo (fady) — but to his mother, who will then pass it on to the girl's mother, who in turn will talk to the father and give him the money. The father will then explain to the male family members who reside locally that the girl is 'seeing' someone, and he will give each of them a share of the money. At this stage, formal relationships between the two families do not take place and parents rarely take such unions too seriously, since they are very unstable and frequently break up.

Yet from this moment the boy can come at any time of the day to see his girlfriend in her village, since they are already accepted as a couple by the girl's family. Half-jokingly, people start using the term vady (spouse) alongside sipa (lover). The boy may further show respect to his girlfriend's parents in various ways-for example, by bringing small 
gifts of firewood or food and by taking part in the household's activities, especially in agricultural work. He does not reside permanently in his girlfriend's village, however, because he has to fulfil various duties in his own village. The young couple enjoy a relationship that is, to a certain extent, already marriage-like, and indeed people refer to the situation of a young girl living by herself and receiving a lover by saying that the girl manao kitokantrano - an expression that comes from mitokantrano ('having a hearth in the house') and can be translated as 'she pretends to have a hearth'.

If the relationship lasts and develops, the boy will soon inform his girlfriend's parents that members of his family will come to do the 'removal of the taboo' (ala-fady). On an agreed date-often chosen with the help of a mpanandro (diviner) so that it brings good luck-a small party called the mpanala-fady (literally, 'givers of the ala-fady'), consisting of a few men from the boy's local descent group, arrives at the girl's parents' house. They explain to the head of the family that the boy and the girl like each other and that they would like the girl to come to live for some time with the boy in their village. If the head accepts, the mpanala-fady gives him a sum of money that is often enough to buy a few chickens and he gives his blessing. As for the tapi-maso, this sum will be divided and distributed among the girl's male relatives. A meal is served-usually chicken and rice- and local rum is offered. If night is about to fall or the journey back will take a long time, the guests are invited to stay for the night. When they return to the boy's village, they take the girl with them. She brings only a small amount of luggage: people in her village and family say, euphemistically, that she is going for a walk (mitsangatsangana). At the boy's village, if possible, the young couple will occupy a room in the parents' house-usually a room on the ground floor. If there is no room available at the parents', the couple will temporarily dwell in a relative's house. The girl lives with her partner's kin and works with the women for several months, and sometimes for much longer. This time is clearly thought of by everyone as a kind of probation, to see whether she can get along well and work with people. During this period, however, the couple is now constantly referred to as vady (spouses) and the word sipa (lovers) is not used any more.

After some time, the boy's father calls his son and tells him that the girl has been among them for long enough. If there have been serious issues during her stay and the parents are concerned that the girl will not make a good wife, they may tell him that she should be taken back to her 
village. If, on the contrary, the parents and family members in the village are satisfied with her, the boy's father says that the tandra vady ('gift for the spouse', often simply called tandra) should now be given to her family. Father and son discuss the possibility of paying for the tandra. Ideally, it should be the father who offers it, but in poor families it is common for the sons to work and save enough to pay for it, although it will always be presented as coming from the father.

The girl is then sent off to her family to announce that the boy's parents will come to give the tandra on a date they have chosen with the help of a mpanandro that will bring good luck to the couple. The girl's relatives prepare for the event. Parents buy chickens and rum. Women start weaving mats and collecting items for the girl's trousseau. Members of the girl's local descent group are invited to attend the meeting.

The representatives of the boy's family attending the tandra vady meeting consist once again of a few men. This time, the party is called the mpanandra-vady ('givers of the tandra vady'). As in the case of the ala-fady, the boy's parents are not among the mpanandra-vady, nor is the boy, who will wait for his wife in his village. When the mpanandra-vady arrives at the girl's village, they do not enter the house straight away but instead stay on the threshold. The girl's relatives insist that they should go further into the house to find a better place, but they refuse. One of the male mpanandra-vady gives a speech explaining that they come in the name of the head of the boy's local descent group. Then he puts a small amount of money (usually a note of 100 or 200 Ariary [A4-8 cents]) into his hat and puts it on the floor, asking for permission to open the door (mivoha varavarana) and enter the house, which is a metaphorical way of asking for the opening of the discussion on the tandra. The girl's relatives respond: 'But you already entered. Please come in, sit in the room.' The mpanandra-vady comes in a bit further but still stays close to the door, as if they were ready to leave. They then explain that the boy and the girl like each other and would like to set up their own hearth in the boy's father's village. The speaker (mpikabary) for the girl's family replies that the girl has already given her consent and so there is nothing they can do to prevent her from leaving, even if no tandra is given. The mpanandravady insists that they want to follow the customs and offer something to the parents. They propose a tandra, in the form of either a sum of money or, more rarely, an ox that they may have brought with them. A discussion then starts that takes the form of a ritualised bargaining on the value of this tandra (for an example, see Dubois 1938: 400-4). During this 
discussion, the mpanandra-vady is exhorted to come further into the room and 'go upstairs' (miakatra) in the house, which is a metaphorical way of asking for a higher tandra.

After an agreement on the tandra is reached, the mpanandra-vady is invited to enter the room to sit in a better place. Up to this point, they have stayed on the western side, where the door is located in all southern Betsileo houses. This time they accept and sit on the eastern side, which is the side where elders and honoured guests should sit. Rum is passed around. The women of the girl's family who were busy cooking the meal are now told to prepare the girl because she will leave the house. During the talks, the girl has been waiting in another room of the house, getting dressed and doing her hair with the help of other women. A meal of chicken and rice is served to the guests and the men of the family, while the women and the girl eat with the children in the kitchen. The rump of the chicken (vodi-akoho), which is normally given to the oldest male present, is given instead to the man who talked in the name of the boy's family, even if he is young and there are elders in the room. This is a sign of respect towards the boy's 'fathers-and-mothers' (ray amandreny — that is, the parents in the classificatory sense and by extension all the senior members of the group), who have now to be honoured as relatives (havana). When the meal is over, the head of the family calls the girl. She appears in her nicest clothes with her hair newly plaited. People bring her luggage, which consists of her personal belongings and also various household items bought for the occasion or given by relatives: suitcases, mats, baskets, clothes, cooking pots, buckets, spoons, a mattress, a bed and so on. The girl's family makes an inventory, calling out each item and writing a list on a small notebook or sheet of paper. This list is for the boy and is given to his representatives. The couple must keep it, because these items belong to the girl and if the couple separates, she will come back to her village and bring these items with her.

The head of the girl's local descent group proceeds to the 'blessing' (tsiodrano). Everyone remains seated but turns their body and face towards the eastern wall of the room. The head of the family explains that the family is losing a girl but acquiring a boy since they are exchanging a daughter for a son (see Dubois 1938: 404). Holding a large cup with water, he asks for God's and the ancestors' blessings, and then blesses the girl, sprinkling her and the audience with water from the cup. Everyone shouts 'Soa tsarà e? ('Be nicely well!'). After the tsiodrano, the head of the 
family enunciates the ancestral fady (taboos) of the girl, which will have to be respected in the new hearth. They are written down in the notebook or the paper used for the inventory to be given to the boy.

The mpanandra vady now sets off with the girl and her luggage. It is taboo for the girl to greet people on her way to her new village. When they arrive at the village, the mpanandra-vady and the girl are welcomed by a large number of the boy's relatives, who have been waiting in the parents' room-usually upstairs in the house. The family meeting that takes place on the boy's side is called mampody vady vao (literally, 'bringing a new spouse home again') or simply vady vao ('new spouse'). The girl is invited to sit beside the boy on the eastern side of the room. The luggage (entana) she brings is placed in the middle of the room, so everyone can see it. The leader of the mpanandra-vady reports on the meeting at the girl's village, detailing the negotiations on the amount of the tandra, and he reads out the list of the girl's luggage and taboos. Then a meal-again consisting of chicken and rice-is served to all, but the girl is given an unusually large share of chicken. She receives a tureen full of rice and her own bowl of loaka (side dish) on a special placemat, whereas young people receive only a plate of rice topped with a tiny piece of chicken and elders share bowls of loaka. A senior female member of the group who has never separated from her husband is asked to bring the first spoon of rice to the girl's and the boy's mouths. During the whole meeting, the couple stays quiet, since they are not expected to talk. After the meal, all the girl's items are placed on the eastern side of the house and she sits in front of them, looking at the eastern wall. All the people present look in this direction, too. The head of the family makes a speech asking God and the ancestors to bless the girl and the couple, and he stresses that the boy's parents have received not a spouse but a daughter. He sprinkles the girl with water, and then her luggage and the audience. When the blessing is over, everybody says 'Soa tsarà e? ('Be nicely well!').

The couple should now live for some time in the boy's parents' house, even if a separate house is already available; ideally, the boy should have built a new house in the period between the ala-fady and the tandra vady. After a month or two, the couple asks the permission of the boy's father to set up their own 'hearth-in-the-house' (tokantrano). If the father agrees, this is announced to the boy's family and friends, who are invited to share the morning meal (sakafo maraina) the day after the couple have moved to their house or to a separate room. This morning meal must be very simple and usually consists of rice broth (vary sosoa), cassava or sweet potatoes, sometimes sweetened with honey. People are invited to eat a small portion 
of the meal, after which they congratulate the couple, wishing them: 'Let your house be hot!' ('Mafanà trano!'). They then depart to leave room for other visitors. With the morning meal completed, the couple can now enjoy having their own hearth in the village.

\section{Marital investigations}

When the potential marriage partner is from a family or a village about which little is known, it is expected that the free descent parents will check the family's ancestry by undertaking an extensive investigation (enquête in French; famotorana in Malagasy). These investigations are not usually conducted during the first stage of the marriage process (the tapi-maso) since relationships easily break up. But if children notify their parents that they would like to go further with the customs $(f o m b a)$ then parents and senior members of the family set off, often on foot and sometimes for more than 100 kilometres, to visit their relatives in the region where their child's lover has his or her 'origins' (fiaviana). I was told that this inquiry may last for weeks, as parents and relatives gather information about the potential partner's family and 'the kind of ancestry' these people have. My Betsileo friends stressed that, when performing such an inquiry, it is important to take the time to travel around the 'places of origin' (usually the villages of the parents and grandparents) of the potential marriage partners. It is also essential to ask only one's relatives, even remote ones, because other people could be friends or, worse, relatives of the family in question, in which case there is a risk of being told lies. One's own relatives are said to be the only trustworthy informants for this kind of inquiry. It is assumed that they will not lie and will take the gathering of information very seriously, because they all have an interest in not having a slave descendant marrying into the family.

Relatives living close to the village of the family under investigation will often have an idea about whether or not these people have slave ancestry. If they do not, they will know how to get more information. Members of their own kinship networks may have relationships with this family and may go to their funerals. At these funerals, they may have listened to the tetiharana and noticed marriages with people from suspicious villages. The final outcome of the parents' inquiry will be that the family is judged 'clean' (madio), 'unclean' (tsy madio) or 'not clear' (tsy mazava). The family's status is considered 'not clear' when, for some reason, the inquiry did not allow the parents to ascertain 'clean' origins. In that case, parents would 
usually not run the risk of discovering in the future that their counterparts are of slave descent and would therefore refuse the marriage, just as they would had they found out the family was 'unclean'.

\section{Conclusion}

Tetiharana (genealogical speeches) and famotorana (marital investigations) are practices that are still central to southern Betsileo culture and society. It seems, however, that these two 'journeys', undertaken to check people's origins, had a slightly different role in the precolonial past. Before abolition, Betsileo olompotsy (commoners) were mainly concerned with marrying equals - that is, members of descent groups who were of equal rank-so their vigilance about origins was directed mainly at contracting isogamous marriages. In the present day, I would argue that these practices have been entirely hijacked by free descendants, who use them to identify slave descendants and ascribe to them unclean or 'unclear' status. In other words, whereas in the past these two practices were an intrinsic part of the elaborate hierarchical systems found in the Malagasy highlands and were used to make distinctions for the purpose of marriage between descent groups according to prestige and rank, today these practices serve one main goal: to avoid marrying slave descendants.

\section{References}

Astuti, Rita. 1995. “The Vezo are not a kind of people”: Identity, difference, and "ethnicity" among a fishing people of western Madagascar.' American Ethnologist 22(3): 464-82. doi.org/10.1525/ae.1995.22.3.02a00010.

Bloch, Maurice. 1993. 'Zafimaniry birth and kinship theory.' Social Anthropology 1(1b): 119-32. doi.org/10.1111/j.1469-8676.1993.tb00245.x.

Dubois, H. 1938. Monographie des Betsileo [Monograph of Betsileo]. Paris: Institut d'Ethnologie.

Evers, Sandra. 2002. Constructing History, Culture and Inequality: The Betsileo in the extreme southern highlands of Madagascar. Leiden: Brill.

Fox, James. 2006. 'Genealogy and topogeny: Towards an ethnography of Rotinese ritual placenames.' In James Fox, ed., The Poetic Power of Place: Comparative perspectives on Austronesian ideas of locality, pp. 89-100. Canberra: ANU E Press. doi.org/10.22459/PPP.09.2006.05. 
Freeman, Luke. 2013. 'Speech, silence and slave descent in highland Madagascar.' Journal of the Royal Anthropological Institute 19: 600-17. doi.org/10.1111/ 1467-9655.12052.

Gelman, Susan A. 2003. The Essential Child: Origins of essentialism in everyday thought. Oxford: Oxford University Press. doi.org/10.1093/acprof:oso/978019 5154061.003.0009.

Huntington, Richard. 1988. Gender and Social Structure in Madagascar. Bloomington: Indiana University Press.

Kottak, Conrad. 1980. The Past in the Present: History, ecology, and variation in highland Madagascar. Ann Arbor: University of Michigan Press.

Parker Pearson, Mike and Denis Regnier. 2018. 'Collective and single burial in Madagascar.' In Aurore Schmitt, Sylviane Déderix and Isabelle Crevecoeur, eds, Gathered in Death: Archaeological and ethnological perspectives on collective burial and social organisation, pp. 41-62. Louvain-La-Neuve, Belgium: Presses Universitaires de Louvain.

Rajaonarimanana, Narivelo. 1996. 'Les sept pilons de fer: Traditions orales du Manandriana (Madagascar) [The seven iron pestles: Oral traditions of the Manandriana (Madagascar)].' Études océan Indien [Indian Ocean Studies] 20: $1-160$.

Regnier, Denis. 2012. 'Why not marry them? History, essentialism and the condition of slave descendants among the southern Betsileo (Madagascar).' $\mathrm{PhD}$ thesis, London School of Economics and Political Science, London.

Regnier, Denis. 2015. 'Clean people, unclean people: The essentialisation of "slaves" among the southern Betsileo of Madagascar.' Social Anthropology 23(2): 152-68. doi.org/10.1111/1469-8676.12107.

Regnier, Denis. 2019. 'Forever slaves? Inequality, uncleanliness and vigilance about origins in the southern highlands of Madagascar.' Anthropological Forum 29(3): 249-66. doi.org/10.1080/00664677.2019.1624501.

Regnier, Denis. 2020. Slavery and Essentialism in Highland Madagascar: Ethnography, history, cognition. London: Routledge. doi.org/10.4324/9781003086697.

Southall, A. 1986. 'Common themes in Malagasy culture.' In Conrad Phillip Kottak, Jean-Aimé Rakotoarisoa and Aidan Southall, eds, Madagascar: Society and history, pp. 411-26. Durham, NC: Carolina Academic Press.

Wilson, Peter. 1992. Freedom by a Hair's Breadth: Tsimihety in Madagascar. Ann Arbor: University of Michigan Press. doi.org/10.3998/mpub.13491. 
This text is taken from Austronesian Paths and Journeys, edited by James J. Fox, published 2021 by ANU Press, The Australian National University, Canberra, Australia.

doi.org/10.22459/APJ.2021.04 